\title{
Sobre las formas personales en las familias Tikuna-Yurí, Sáliba-Piaroa (y Andoke). Parentesco, contacto o tipología.
}

María Emilia Montes Rodríguez ${ }^{1}$

\begin{abstract}
Resumen
Se discute una hipótesis sobre la relación genética de tres lenguas y familias del Noroeste Amazónico, consideradas hasta el momento como aisladas y sin conexiones históricas. La expresión de la categoría de persona es el elemento central en esta presentación de datos y problemas cuyo propósito es ilustrar con material empírico las cuestiones a debatir. Dada la relativa estabilidad diacrónica (no aceptada por todos los autores) de los paradigmas de persona, podría aceptarse alguna conexión entre una familia del borde amazónico (SálibaPiaroa) y una familia cuyos supervivientes están hoy en la ribera del Amazonas y sus afluentes (Tikuna-Yurí); sin embargo elementos tipológicos y areales ya descritos para otras lenguas y familias deberán ser mejor considerados para analizar las relaciones de contacto, dada la historia regional. La lengua de los andokes, que permanece como lengua aislada en una región amazónica intermedia, ofrece algunas claves tipológicas a considerar y sugiere que es necesario ampliar la comparación a otras familias del área considerada en temas como las categorías expresadas por la persona; los sistemas de género o clases nominales; los nombres inalienables y las fronteras de la oposición verbo nominal; temas en los que el estado de la cuestión dista mucho de estar bien establecido.
\end{abstract}

Palabras clave: Tipología. Tikuna. Yurí. Andoke. Sáliba. Piaroa. Persona. Amazonia. Orinoquia. Colombia.

\section{Resumo}

Discutimos de maneira não conclusiva uma hipótese sobre o parentesco genético de três línguas do Noroeste da Amazônia até agora consideradas isoladas e sem conexões históricas. A expressão da categoria de pessoa é o elemento central na apresentação de dados cujo objetivo é ilustrar problemas com material empírico. Dada a relativa estabilidade diacrônica (fato não aceito por todos os autores) dos paradigmas da pessoa, é factível uma conexão entre uma família da fronteira da Amazônia (Saliba-Piaroa) e uma família cujos sobreviventes estão agora nas margens do Amazonas e seus afluentes (Tikunas-Yuri), mas os elementos tipológicos e areales já descritos para outras línguas e famílias devem ser melhor considerados para analisar as relações de contato, dada a história da região. A lingua dos andokes, que permanece isolada em uma região intermediária da Amazonia, oferece algumas chaves tipológicas para estender a comparação com outras famílias na área considerada, em as categorias expressas pela pessoa. Também no que respeita aos sistemas de gênero, nome alienável/inalienável, oposição verbo-nominal, temas em que a situação está longe de ser bem estabelecida.

Palavras-chave: Tipologia. Tikuna. Yurí. Andoke. Sáliba. Piaroa. Pessoa. Amazônia. Orinoquia. Colômbia.

1 Universidad Nacional de Colombia, Facultad de Ciencias Humanas, Dpto. de Lingüística, memontesr@unal.edu.co. 


\section{Ubicación y filiación lingüística}

Los grupos étnicos y lingüísticos que son objeto de esta presentación están hoy en día en tres regiones bien diferentes y separadas, sin relaciones actuales de contacto o intercambio. Dos de las lenguas - tikuna y andoke ${ }^{2}-\mathrm{se}$ han considerado durante muchos años como lenguas aisladas y las otras dos lenguas - sáliba ${ }^{3}$ y piaroa - consitituyen una pequeña estirpe de proyección regional. De norte a sur en la zona de frontera oriental entre Colombia y Venezuela ${ }^{4}$ tenemos en primer lugar a los sálibas en la Orinoquia, donde están además grupos de la familia Guahibo. En la zona de transición entre sabana orinocense y selva amazónica están los piaroa. En esa región hay además grupos de la familia Arawak (curripaco, piapoco, baniva) y grupos Puinave (familia Makú-Puinave). Hacia la región del Vaupés están los grupos de la familia Tukano (cubeo, yurutí, tanimuca, tuyuca, macuna, barasana, tucano, tatuyo, desano, piratapuyo, wanano, pisamira, eduria, carapana, siriano) que han estado en contacto permanente con las lenguas Arawak. Otras lenguas Arawak del Vaupés se han debilitado notablemente y algunas se consideran extintas (cabiyarí). Por otra parte, completan ese panorama las lenguas de los nómades agrupadas en la familia Makú (hupda, cacua, yuhup, nukak, nadëb) y la lengua recientemente extinta de los carijona (Caribe).

En la región del interfluvio Caquetá-Putumayo se encuentra el andoke (clasificado como aislado) conviviendo con lenguas, o al menos reductos lingüísticos de las familias Bora-Miraña (bora, miraña, muinane, nonuya), con el Uitoto (dialectos del uitoto, okaina). Se han reportado en el río Bernardo, afluente del Cahuinarí, asentamientos yurí (serían los mismos 'caraballo' reportados en la década de los años 60 por un episodio de contacto violento entre indios aislados y colonos, hoy quizá en 'aislamiento voluntario'). Lenguas Arawak - resígaro y tariano - se hablaban hasta hace poco y hay documentación sobre las mismas, pero otras han desaparecido: uainumá (otrora poderosos y numerosos según las crónicas), passé, mariaté y jumaná, lenguas registradas por Martius e identificadas como Arawak.

Los actuales Tikuna colombianos están fundamentalmente en la porción del Trapecio Amazónico, una región interfluvial Putumayo/Iça-Amazonas/ Solimões. Sobre ambos ríos se ubican hoy poblaciones tikunas en Brasil y en Colombia; en el Perú están también sobre la ribera y en algunos afluentes de la

2 Agradecemos a Jon Landaburu a quien consultamos sobre algunos planteamientos de este artículo durante el 2011. Lo aquí expresado es exclusivamente responsabilidad de la autora. Los datos del andoke se han tomado de las fuentes publicadas de Landaburu.

3 Algunas fuentes y ejemplos del sáliba y del piaroa, se trabajaron conjuntamente con Hortensia Estrada, investigadora del Instituto Caro y Cuervo. Agradecemos su aporte y comentarios al presente texto.

4 Para ubicaciones remitimos a la obra de Queixalós y Lescure, 2000. 
margen sureña. Comparten hoy en día su territorio con los Cocama (lengua de léxico mayoritariamente Tupí pero con una gramática no tupí, como resultado de cambios inducidos por contacto, según Cabral 1995) y con la gente de lengua yagua, lengua superviviente de la familia Yagua-Peva.

¿Por qué esta comparación entre lenguas aisladas o familias de proyección regional sin contactos ni relaciones aparentes hoy en día? Respondemos a una sugerencia hecha por un lingüista brasilero (Jolkesky 2009), quien esbozó una serie de rasgos compartidos entre estas lenguas, además de incluir la lengua hoti. Esboza la hipótesis de un tronco 'Macro-Daha' que incluiría la familia Sáliba (Sáliba y Piaroa) y las lenguas aisladas Hoti, Tikuna ${ }^{5}$ y Andoke: "A partir de comparação semelhante [sistemas pronominais] em mais de 100 línguas do continente, representando todas as famílias lingüísticas e incluindo todas as línguas classificadas como isoladas, selecionei aquelas que apresentavam idiossincraticamente traços formais e funcionais em comum". Retomamos sólo el tema de las formas personales que consideramos interesante y válido. No incluimos por ahora los datos del hoti, lo que sin duda es una fase ulterior y necesaria. Consideramos que otros rasgos que plantea Jolkesky ${ }^{6}$ son esencialmente parámetros tipológicos generales insuficientes aún para separar una familia de otras familias de la gran área del medio Amazonas y del Noroeste Amazónico y así mismo, insuficientes para separar grupos dentro de la familia. Tampoco nos referiremos a datos de fonología. Basta señalar que ese autor propone rasgos tipológicos y areales muy extendidos como indicios de parentesco genético. Reconocemos que en el área Amazonia noroccidental y borde amazónico (Orinoquia) el asunto de la prosodia (tonos, acento tonal, longitud vocálica, nasalidad como suprasegmento) parece un problema constante en el análisis de diversas lenguas y familias. Estos puntos empiezan a ser abordados de manera preliminar y suponen un trabajo teórico y comparativo de largo aliento (cf. Gómez-Imbert y Ospina 2010).

Por otra parte, algunos datos etnohistóricos harían suponer que los contactos y las migraciones - forzadas o no por la conquista europea pudieron haber sido mucho más activos de lo que son hoy, cuando gran parte de las redes se han roto y cuando el panorama original en torno a los grandes ríos Amazonas-Solimões, Orinoco y Río Negro, Putumayo-Iça y CaquetáJapurá ha sido profundamente modificado por fenómenos como las guerras

5 Durante mucho tiempo se consideró al tikuna como aislado, pero a partir del análisis de Orphão de Carvalho (2009) puede sustentarse una relación con la lengua de los Yurí, tal y como fue registrada por Martius (1863 y 1867).

6 Este autor plantea como elementos propios del tronco hipotético la "morfologia aglutinante e sufixal; presença de prefixos pronominais possessivos, anteposição do genitivo e dos pronomes demonstrativos em relação ao nome, presença de tom e ausência de laterais e da nasal velar no sistema fonológico; presença de prefixos pronominais possessivos e anteposição do genitivo e dos pronomes demonstrativos em relação ao nome". 
tempranas entre potencias europeas, el consiguiente tráfico de esclavos (que implicó grandes desplazamientos humanos), las misiones (que generaron reagrupamientos y cambios en los patrones de residencia y de intercambio étnico), la extinción física y muy temprana de muchos grupos y finalmente - y más recientemente - el etnocidio cauchero que afectó principalmente el interfluvio Caquetá-Putumayo. Algunos elementos de esta compleja historia de intercambios - forzados por razones exógenas - se trazan en el trabajo de Goulard (2011:ix) sobre el Noroeste Amazónico después de los jesuítas:

En el transcurso de esta 'historia' se observa que numerosos rasgos de las poblaciones que vivían allí habían sido modificados. En consecuencia, los grupos humanos habían conocido recomposiciones étnicas, aun cuando poco se sabe de los períodos anteriores a la conquista. Es necesario considerar, por lo menos, que las poblaciones que ocupaban la región en 1775 son el resultado de un sustrato ya recombinado, lo que hace que el concepto de 'paisaje étnico' sea polisémico y fluido, lo cual se verifica en diversos campos de estas sociedades y que, entonces, resulten de bastantes préstamos, por intercambios aceptados o no.

Creemos que hace falta priorizar la mirada areal y tipológica sobre el afán por la reconstrucción y el parentesco genético en las lenguas aisladas y las familias pequeñas. Ello es una tarea pertinente y necesaria en el actual estado de investigación sobre un sector de la gran región amazónica y orinocense, frontera de Colombia, Venezuela, Brasil y Perú.

\section{Algunos datos etnográficos}

Los Piaroa son 14500 en Venezuela según censo del 2001 y menos de un centenar en Colombia. La denominación endógena es wo'tiheh; tienen una fuerte identidad étnica y un alto grado de conservación de la lengua (Ethnologue). Se encuentran principalmente en el Estado del Amazonas sobre el Orinoco y en la ribera de los caños Piojo, Mure, Grulla, Limón de Parhueña y a orillas del río Chivapure en el estado de Bolívar. En Colombia están en el departamento del Vaupés, igualmente cerca de la ribera orinocense y del río Guaviare (Mosonyi 2000:657). Comparten hoy su territorio con grupos de lengua Arawak como los Piapoko y con algunos núcleos sikuani. En Colombia se calcula que hay 2231 sálibas, según censo del Plan de Protección a la Diversidad Étnica ${ }^{7}$, PPDE 2008. Están al norte de los piaroa en torno al poblado de Orocué, cerca de las riberas del río Meta y del caño Duya; en sus 'conucos' cultivan la yuca brava. Habitan suelos pobres y su entorno presenta alto deterioro ambiental. Han asimilado elementos de la cultura campesina regional, según Estrada (1995: xxi). Esta

7 Iniciativa del Ministerio de Cultura de Colombia liderada por Jon Landaburu, asesor ministerial. 
misma autora cita a Gilij (1780:174) y luego a Brinton (1891:245), Chamberlain (1913), Rivet (1920: 12-20) y Loukotka (1935: 151) quienes habrían establecido y refrendado el parentesco sáliba-piaroa.

Los Andoke ocupan hoy las riberas del medio Caquetá, siendo este también reconocido como su territorio ancestral. Los andoke del siglo XX y XXI (300 aproximadamente en la actualidad) son el fruto de un proceso de reconstitución étnica pues esta gente, cuya población antes numerosa (alrededor de 10 mil) fue "prácticamente aniquilada" durante el período del caucho de finales del siglo XIX y principios del siglo XX. Según Landaburu y Pineda (1984:26), "a principios del siglo XX la región estaba densamente poblada, aunque la población pudo ser aún mayor en los decenios anteriores a la conquista ibérica" y había también un fuerte comercio intertribal. Los pueblos caribes y los miraña tenían una presencia notable en las orillas del río Caquetá. Se cita a Martius quien se refiere a la presencia debilitada de los antes poderosos uainumás (Arawak) en el Cahuinarí y de "diversos grupos yurí" (pg. 29). Los sobrevivientes que quedaron en el territorio y los pocos que huyeron desde el Perú (a donde fueron deportados durante las caucherías) se agruparon bajo el mando de Yiñeko y en sus lugares ancestrales "iniciaron un proceso de resurgimiento étnico" (pg. 32 y 33). Según los mismos autores, se produjeron cambios fundamentales en la organización social que implicaron la agrupación de los linajes sobrevivientes en una unidad mayor, reorganización de reglas matrimoniales, asilo a individuos de linajes no andoques y a un grupo huitoto fugitivo. La lengua de un grupo antes muy diversificado en clanes (¿y posiblemente en dialectos?) también habría experimentado cambios fundamentales a raíz de la reagrupación y de los nuevos contactos.

Los Andoke son 'Gente de centro' y se desenvuelven hoy (como lo hicieron ayer) en contexto interétnico con otros sobrevivientes de los grupos uitoto, nonoya, bora, miraña, okaina. Son además "gente de coca y ambil" lo que implica la pertenencia a un complejo definido por rituales compartidos en torno a estas plantas fundamentales en la cultura y en los intercambios internos y entre grupos.

Los Tikuna son hoy una población de más de 40 mil personas en tres países cuyas principales aldeas modernas están en las riberas amazónicas. Una parte de los tikunas más conservadores habita en los afluentes, principalmente los afluentes de la margen norte del Amazonas y en algunos afluentes del Putumayo en la zona interfluvial conocida como 'tierra firme'. Son depositarios de una cultura mayor y más diversa del Noroeste Amazónico. Recientemente se ha establecido que hay una relación de filiación entre las lenguas de los Tikuna amazónicos y la lengua de los extintos Yuri ${ }^{8}$ (una denominación ambigua

$8 \mathrm{O}$ al menos la de los grupos con ese exónimo que fueron objeto de la recolección de datos por parte de los viajeros Martius, Spix y Wallace en Martius 1863 y 1867. La relación entre 
que no necesariamente se refiere a una entidad étnica única) del interfluvio Putumayo-Caquetá. Ambos pueblos habrían compartido territorios con grupos Arawak o posiblemente Arawak (uainumá, jumaná, mariaté, cauixana, passé) en el siglo XIX. Los jesuítas presentes en el medio Amazonas de 1639 hasta 1767 no nombran a los Yurí, pero luego aparecen señalados por diferentes viajeros y cronistas de siglos posteriores (cf. Goulard y Montes en prensa). Los tikunas de hoy se caracterizan por el uso y consumo de la yuca dulce, el uso del tabaco, los rituales de paso con cierto tipo de máscaras y el encierro de la mujer púber. No son la excepción a una larga historia de contactos intensos y tempranos, pues se habla de ellos (con diferentes denominaciones, algunas dudosas) desde el inicio de la conquista y aparecen en los informes de la época de las misiones como enemigos de los Omagua (Tupí), y de otros grupos habitantes de las islas y de la várzea. Es notable en el tikuna un influjo reciente de la lengua geral (Tupí).

\section{Las formas personales}

Entre las familias Sáliba-Piaroa y Tikuna-Yurí hay una serie de coincidencias interesantes entre las formas personales prefijadas tanto a los nombres como a los verbos, como lo señaló Jolkesky 2009. Sin embargo hay hechos que no pueden ignorarse: a) El tikuna tiene un único conjunto de formas personales prefijales para las diferentes funciones sintácticas. b) El sáliba y el piaroa presentan un panorama mucho más complejo desde el punto de vista morfológico, pues las formas de persona son tanto prefijales como sufijales. El paradigma andoke (datos en Landaburu 2000:284) coincide poco con SálibaPiaroa y con Tikuna-Yurí e incluye sub-categorías específicas a esta lengua.

Para el yurí tomamos los datos del vocabulario de Martius (1863), transcrito y analizado por nosotros (Goulard y Montes, en prensa). Las iniciales que aparecen en ocasiones al lado de datos yurí corresponden a los tres recolectores del vocabulario, compilado en diferentes lugares de la Amazonia: Spix, S; Wallace, W y para el resto de ítems, Martius sin indicación. La segmentación de las formas de tercera persona es nuestra a partir de los ejemplos disponibles. Los autores reconocen y segmentan el prefijo de primera persona.

\section{Prefijos de los nombres (inalienables)}

El conjunto de formas prefijadas a los nombres, con sus variantes y alomorfos ${ }^{9}$ es el siguiente:

los datos del vocabulario yurí de Martius y el tikuna actual fue propuesta por Orphão de Carvalho, 2009. No hay aún correspondencias ni medición léxico-estadística sobre esta agrupación propuesta.

9 Convenciones y grafías: La grafía jurí de Martius usa $t s c h$ - que alterna con $s$ - en algunos 
Tabla 1: Prefijos de los nombres y en piaroa, sáliba, tikuna y andoke

\begin{tabular}{|c|c|c|c|c|c|c|c|}
\hline & P1S & P2S & P3SM & P3SF & P1PL & P2PL & P3PL \\
\hline $\begin{array}{l}\text { Piaroa } \\
\text { Mosonyi, } \\
\text { 2000:661 }\end{array}$ & $t \int-$ & $\mathrm{k}-/ \mathrm{k}^{\mathrm{w}}-$ & Ø- & $\mathrm{h}-/ \mathrm{h}^{\mathrm{w}}{ }_{-}$ & $t-$ & $\mathrm{k}-/ \mathrm{k}^{\mathrm{w}}$ & $\mathrm{t}^{\mathrm{h}_{-}}$ \\
\hline $\begin{array}{l}\text { Sáliba } \\
\text { Estrada, } \\
\text { 1995:84 }\end{array}$ & $c-$ & $\begin{array}{l}\mathrm{k}-/ \mathrm{k}^{\mathrm{w}}-/ \\
\mathrm{g}-\end{array}$ & $\begin{array}{l}\varnothing-/ \\
h-\end{array}$ & $\mathrm{x}^{-}$ & t- & $\begin{array}{l}\mathrm{k}-/ \\
\mathrm{k}^{\mathrm{w}} / \mathrm{g}-\end{array}$ & h- \\
\hline \multirow[t]{2}{*}{ Tikuna } & $\begin{array}{l}\text { cà-/ cì-/ } \\
\text { caù-/ cò- }\end{array}$ & $\begin{array}{l}\text { kù- } \\
\text { kùì-/ } \\
\text { kì- }\end{array}$ & dã-/dĩ- & gĩ-/ĩ- & tà-/tì- & pé- & tá-/tí- \\
\hline & & & \multicolumn{2}{|l|}{ tur-bã } & & & tur-bã \\
\hline $\begin{array}{l}\text { Yurí } \\
\text { Martius, } \\
1863\end{array}$ & $\begin{array}{l}\text { tschu-/ } \\
\text { tschö/ } \\
\text { tschä-/ } \\
\text { tscho-/ } \\
\text { tsch-/ } \\
\text { tscha/ } \\
\text { su- }\end{array}$ & & $\begin{array}{l}\text { no-/ } \\
\text { ne- }\end{array}$ & & & & \\
\hline \multirow{3}{*}{$\begin{array}{l}\text { Andoke } \\
\text { Landaburu, } \\
2000: 284\end{array}$} & O- & ha- & ja- & dĩ-/ $\tilde{1}^{-}$ & ka- & $\mathrm{k} \tilde{\gamma}^{-}$ & $\tilde{\gamma}^{-}$ \\
\hline & & & $\begin{array}{l}\text { no } \\
\text { visible }\end{array}$ & $\begin{array}{l}\text { no } \\
\text { visible }\end{array}$ & & & $\begin{array}{l}\text { no } \\
\text { animado, } \\
\text { poco } \\
\text { individua- } \\
\text { lizado }\end{array}$ \\
\hline & & & ó- & о̃- & & & $\Lambda^{-}$ \\
\hline
\end{tabular}

El análisis morfológico de sáliba y piaroa considera vocales epentéticas, fonológicamente condicionadas por el nombre al que se prefijan $\{C-\}$, mientras que tikuna y yurí tendrían un morfema $\{C V(V)-\}$ con variaciones vocálicas condicionadas por el nombre al que se prefijan.

En tikuna la forma $\{$ tu-bã $\}$ es de $3 a$. persona singular o plural y puede usarse prefijada a nombres inalienables como señal de respeto y cercanía afectiva.

En andoke la 2a. persona plural $\{\mathrm{k} \tilde{y}-\}$ es similar a la de sáliba y piaroa (y a la forma singular del tikuna); la 3a. persona singular femenino (alomorfos

casos. En andoke y tikuna se usa escritura fonológica. En tikuna /c/ es pronunciada como palatoalveolar africada sorda [t $\int$ ]. En sáliba también se usa escritura fonológica, /c/ es palatal oclusiva sorda. Abreviaturas: P es Persona; 1, 2 y 3, primera, segunda y tercera respectivamente; $\mathrm{S}$ singular; PL plural. 
$\{$ dĩ-, $\tilde{1}-\})$ es similar a una de las formas tikunas para tercera singular masculino $\{$ dĩ-\}, e idéntica a la forma tikuna de femenino $\{\tilde{1}-\}$. Sin embargo, las formas de tercera persona se expanden pues categorizan los rasgos 'animado', 'visible', así como 'individualizado'.

Son los nombres inalienables los que prefijan formas personales. Damos a continuación ejemplos de la ocurrencia de esos prefijos:

Tabla 2: Ejemplos de prefijos de nombres en piaroa $^{10}$, sáliba ${ }^{11}$, tikuna, andoke

\begin{tabular}{|c|c|c|c|c|}
\hline & $\begin{array}{c}\text { Piaroa } \\
\text { (Mosonyi, } \\
\text { 2000:861) }\end{array}$ & $\begin{array}{c}\text { Sáliba } \\
\text { (Estrada, } \\
\text { 1995:85, 87, 91) }\end{array}$ & Tikuna & $\begin{array}{c}\text { Andoke } \\
\text { (Landaburu } \\
\text { 2000:274, 283) }\end{array}$ \\
\hline P1S & $\begin{array}{l}\text { tf- ĩrẽhæ̃ "mi } \\
\text { tierra" }\end{array}$ & $\begin{array}{l}\text { c-ĩxu-xũ "mi } \\
\text { casa” }\end{array}$ & caù-dẽ "mi hijo" & o-dobĩ "mi mano" \\
\hline $\mathrm{P} 2 \mathrm{~S}$ & $\begin{array}{l}\text { k"- ĩrẽhẽ "tu } \\
\text { tierra" }\end{array}$ & $\mathrm{k}^{\mathrm{w}}$-a-e "tu papá" & kù- dẽ "tu hijo" & ha-sea "tu ropa" \\
\hline P3SM & $\begin{array}{l}\text { Ø-ĩrẽhæ̃ "su } \\
\text { tierra" }\end{array}$ & $\begin{array}{l}\text { h-a-e "papá de } \\
\text { él" }\end{array}$ & dã-dẽ "hijo de él" & $\begin{array}{l}\text { ja-tai "cabeza de } \\
\text { hombre o animal } \\
\text { clase } 3.1 \text { " }\end{array}$ \\
\hline \multirow[t]{2}{*}{ P3SF } & $\begin{array}{l}\mathrm{h}^{\mathrm{w}} \text { - ĩrẽhæ̃ "su } \\
\text { tierra de ella" }\end{array}$ & $\begin{array}{l}\text { x- o-xu "mamá } \\
\text { de ella" }\end{array}$ & $\begin{array}{l}\text { gĩ-dẽ, î- dẽ "hijo } \\
\text { de ella" }\end{array}$ & $\begin{array}{l}\text { dĩ-pódi "cara } \\
\text { de mujer o de } \\
\text { animal clase } 3.2 "\end{array}$ \\
\hline & & & & $\begin{array}{l}\text { õ-pyko "casa } \\
\text { de ella" (ella } \\
\text { invisible) }\end{array}$ \\
\hline P1PL & $\begin{array}{l}\text { t-ĩrẽhæ̃ "nuestra } \\
\text { tierra" }\end{array}$ & $\begin{array}{l}\text { t-i-ju } \\
\text { "nuestra(s) } \\
\text { cabeza(s)" }\end{array}$ & $\begin{array}{l}\text { tà-dẽ "nuestro } \\
\text { hijo" }\end{array}$ & $\begin{array}{l}\text { ka-hakojõẽ } \\
\text { "nuestro vecino" }\end{array}$ \\
\hline P2PL & $\begin{array}{l}\mathrm{k}^{\mathrm{w}} \text { - ĩrẽhæ̃ } \\
\text { "tierra de } \\
\text { ustedes" }\end{array}$ & 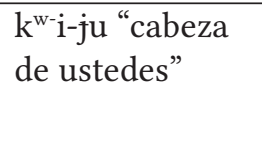 & $\begin{array}{l}\text { pe- dẽ "hijo de } \\
\text { ustedes" }\end{array}$ & $\begin{array}{l}\text { kỹ-haý } \Lambda s i \\
\text { "hermano mayor } \\
\text { de ustedes" }\end{array}$ \\
\hline \multirow[t]{2}{*}{ P3PL } & 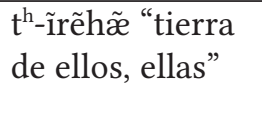 & $\begin{array}{l}\text { h-i-ju "cabeza } \\
\text { de ellos, ellas" }\end{array}$ & $\begin{array}{l}\text { tá-dẽ "hijo de } \\
\text { ellos, ellas" }\end{array}$ & $\begin{array}{l}\text { ỹ-ádu } \\
\text { "guacamaya de } \\
\text { ellos" }\end{array}$ \\
\hline & & & $\begin{array}{l}\text { tur-bã-dẽ "hijo } \\
\text { de él, ella, ellos o } \\
\text { ellas (respetuoso, } \\
\text { ritual)" }\end{array}$ & \\
\hline
\end{tabular}

10 Ejemplos de Mosonyi con segmentación de Estrada, a partir de propuesta en curso de análisis.

11 Los ejemplos 'cabeza de ustedes' y 'cabeza de ellos' son aporte de Estrada, 2012. 
El sáliba presenta dos particularidades a destacar:

a) Exige la presencia de los morfemas de clase nominal con los nombres dependientes.

$\mathrm{k}^{\mathrm{w}}$-a-e "tu papá"

Índice persona 2-padre-Clase Nominal 1a

b) Aunque aparentemente son marginales, tiene formas de persona sufijales, esto para la $1 \mathrm{P} \mathrm{S}\{-\mathrm{d}\}$ y para la $2 \mathrm{PP}\{-$ do $\}$, según condicionamientos morfofonológicos (consonante o vocal inicial en el radical):

da-d-e "mi abuelo"

abuelo-P1S-Clase Nominal 1a (Estrada 1995:85 y 87)

\section{Oposición entre nombres inalienables y alienables}

Un hecho relevante - tipológico y areal - es la existencia de nombres dependientes o inalienables y la labilidad de la frontera entre estos dos subconjuntos de nombres.

En sáliba los nombres independientes o alienables anteponen un determinante posesivo con la forma personal, pero también exigen expresar la concordancia (Estrada 1995:89):

c-o-de

bate-de 'mi batea'

P1S-Vocal epentética-Clase Nominal 8

BATEA-Clase Nominal 8

En esta lengua hay procedimientos morfológicos que desencadenan una cierta indiferenciación entre alienables e inalienables, lo que se deduce a partir de los ejemplos presentados y del análisis que la autora hace de 5 tipos de posesión (Estrada 1995:84-91).

Landaburu (2000:283) señala para el andoke que "los nominales no relativos o absolutos pueden recibir la marca de dependencia sin que esto sea obligatorio. El paradigma de sus índices prefijados es algo distinto al de los índices de nombres relativos". Igualmente de manera fácil, un nombre independiente se convierte en dependiente simplemente adoptando la forma prefijal:

ádu 'guacamaya'

Ỹ-ádu 'guacamaya de ellos'

En piaroa se señala algo similar puesto que los sustantivos no poseídos (alienables) añaden las vocales $/ \mathrm{i}, \tilde{\mathrm{i}}, \mathrm{u} /{ }^{12}$ :

12 Condicionamientos morfofonológicos regidos por el radical nominal determinan la vocal que se inserta. En tikuna, una lengua $\mathrm{CV}$, la vocal es del prefijo pero variará en función de los rasgos de la consonante o vocal del radical nominal. 
[...] para convertir un sustantivo no poseído en uno poseído, basta generalmente anteponer al radical los prefijos personales normales que funcionan igualmente con los radicales poseídos. Tal yuxtaposición sería virtualmente imposible en otras lenguas del área [...] para convertir un sustantivo poseído en uno no poseído [...] basta emplear el prefijo de tercera persona singular o plural, sin otras modificaciones... (Mosonyi 2000:661)

kurodæ 'machete'

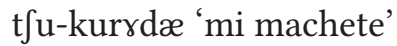

rẽhẽ 'tierra'

t $\int \tilde{1}$-rẽh æ̃ 'mi tierra'

El hecho de tener como forma de tercera persona la marca cero hace que esta diferencia desaparezca en ese contexto, algo análogo a lo que ocurre en sáliba (Estrada, comunciación personal 2012):

Piaroa: ø- $i w e k^{2} a$ 'hueso de él','hueso en general'

En otras lenguas Arawak, como el curripaco, Mosonyi (2000:646-647) señala un procedimiento morfológico explícito, a través de la sufijación de un morfema $-t i$ que permite e indica ese cambio:

nú-talikana "mi jefe"

talikana-ti "jefe"

En tikuna no es posible pasar fácilmente de un subconjunto al otro simplemente adoptando las marcas o construcciones propias de cada subgrupo. Los nombres independientes o alienables anteponen una forma personal genitiva. No hay concordancia. Tampoco hay formas explícitas de señalar el cambio de grupo. El prefijo es un argumento obligatorio de los nombres dependientes o inalienables. La forma de tercera persona masculina singular adquiere el valor de forma genérica, no poseída.

cau-erú 'mi cabeza'

P1-CABEZA

dã-erú 'cabeza de él, cabeza'

co-ru airú 'mi perro'13

P1s-genitivo PERRO

dõ-ru airú 'su perro'

P3S-genitivo-PERRO

Imposible: *cau-airú "mi perro" *co-ru erú "mi cabeza"

13 Variantes dialectales ribereñas ca-ru airú, na-ru airú 
El yurí parecería tener la misma diferencia entre nombres dependientes e independientes y coincide tanto la morfología como el contenido semántico. La mayoría de los ejemplos disponibles son formas en primera persona que refieren a partes del cuerpo o a parentesco:

tschu-tinäho $M$, su-ineu

tsch-uwá M "oreja"

"brazo (mío)"

"cabello"

Hay algunos ejemplos de tercera persona masculino singular que coinciden formalmente con el tikuna de hoy ${ }^{14}$. Los nombres de 'partes' de un todo o de objetos del ámbito personal son dependientes:

nepenüoli W "cuerda"

nehipe W "hamaca"

noomé "remo"

Unos pocos ejemplos parecerían mostrar que - como en andoque - un nombre dependiente puede convertirse en independiente citándose sin el prefijo, si los paréntesis del documento fuente indican opcionalidad:

tschu-gerühó M su-kiriu S (tcho)kireú "cabeza"

(tch)upéri "barba"

El andoke presenta un sistema de clase nominal muy central en la predicación y que determina las formas personales de tercera persona; el tikuna tiene tres géneros o clases que no se expresan en los contextos aquí considerados. El sáliba presenta una clara expresión morfológica de la concordancia de clase con el nominal en el contexto que analizamos (formas de persona + nombres inalienables/alienables).

Se constata que hay diferencias importantes en en el inventario de los prefijos, así como en las categorías que expresan los nombres en cada una de estas lenguas, y finalmente, en el funcionamiento de esos prefijos.

\section{Prefijos de los verbos, índices de persona}

En andoke tiene una organización sintáctica dual en la que hay un conjunto de 'índices referenciales' que son la palabra base del 'asertivo' (elemento indispensable de la construcción predicativa); estos índices también se prefijan a los verbos:

14 La variación en las vocales del prefijo aparece aquí ilustrada en yurí para el prefijo de la 3a persona, prefijo que hoy es en tikuna invariable con los nombres. En tikuna sólo la 1a persona muestra alomorfos cuya vocal está condicionada por el radical nominal. 
$\mathrm{h} \Lambda \mathrm{p} \Lambda$ b-aya- $\varnothing \quad$ "es una boa" (Landaburu 1993:1)

boa modalidad afirmativa-indice de clase 3.1-tópico

ja-o-do-kỹ b $\Lambda \mathrm{i} \quad$ "yo la conozco"

índice de clase 3.1-yo-saber-genérico 1 asertivo+índice de clase 1

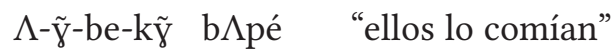

índice de clase 1-índice de clase 3.3-comer-genérico 1 asertivo:índice de clase $1+$ pasado

(Landaburu 2000:280-281)

En piaroa y en sáliba la situación es muy diferente. Hay que considerar - con el verbo - dos conjuntos diferentes relacionados con el tiempo y la modalidad o posiblemente con el alineamiento sintáctico. Las formas personales se expresan con sufijos, además del conjunto de prefijos similares a los de los nombres. Los sufijos son formalmente diferentes de los prefijos.

Para el piaroa Mosonyi (2000:662) establece que en presente y copretérito (afirmativo y negativo) el sujeto se sufija al verbo. Anota que tanto el sujeto como el objeto se pueden expresar de manera externa a traves de nominales o pronombres.

\section{Tabla 3: Formas sufijales del verbo en el futuro, piaroa} (a partir de Mosonyi)

\begin{tabular}{|l|l|}
\hline P1S & -sæ \\
\hline P2S & -hæ \\
\hline P3SM & - \\
\hline P3SF & -hu \\
\hline P1PL & -ætih $\tilde{~}$ \\
\hline P3PL & -ti \\
\hline
\end{tabular}

Según los ejemplos de Mosonyi, la forma usada para 'ustedes' P2PL es igual a la forma de 'nosotros'.

Ejemplos en Mosonyi (ibidem):

adi'tisæ (aditi-sæ) "yo trabajo"

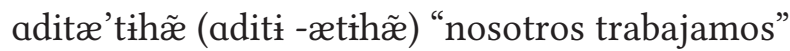

El autor formula así lo que ocurre con el futuro y los verbos intransitivos (negrilla nuestra): 
El futuro tiene la característica de utilizar simultáneamente prefijos y sufijos personales (...) En principio, el prefijo indica sujeto, y el sufijo, objeto, a menos que el verbo sea intransitivo, en cuyo caso el sufijo también indica el sujeto. Hay que agregar que el sufijo personal es en muchos casos, opcional. Ello implica que el sujeto quede indicado solamente por el prefijo, y que el objeto aparezca como externo en lugar de interno... (Mosonyi, ibidem)

Tabla 4: Formas prefijales del verbo en el futuro, piaroa

\begin{tabular}{|l|l|}
\hline P1S & $\mathrm{t} \int-/ \mathrm{d}-$ \\
\hline P2S, P2PL & $\mathrm{k}^{\mathrm{w}-}$ \\
\hline P3SM & $\varnothing-$ \\
\hline P3SF & $\mathrm{k}^{\mathrm{h}_{-}}$ \\
\hline P1PL & $\mathrm{t}^{-}$ \\
\hline P3PL & $\mathrm{t}^{\mathrm{h}_{-}}$ \\
\hline
\end{tabular}

Para este conjunto de prefijos, el autor señala que por condicionamientos morfofonológicos (radical que inicia con vocal o con consonante) aparece el alomorfo d- y además que todas estas formas se pueden convertir en "infijos insertos entre la primera y la segunda sílaba del radical”:

t $\int-\tilde{a} d i ̃ t-\tilde{æ}^{\prime} k^{w} \tilde{a}-s \tilde{e}$

P1S-trabajar-Futuro-P1S

p $\tilde{\mathfrak{X}}-\mathbf{d}-\tilde{\mathfrak{X}}^{\prime} \mathbf{k}^{\mathrm{w}} \tilde{\mathrm{a}}-\mathbf{s} \tilde{\mathfrak{a}}$

decir-P1S-Futuro-P1S
"Yo trabajaré" (con prefijo y sufijo, nasalización que ocurre sobre las personas singulares ${ }^{15}$ )

En sáliba el panorama es muy similar al del piaroa. Además de condicionamientos morfofonológicos, son la valencia y el carácter activo o no del verbo, los que finalmente determinan la forma y ubicación de la forma personal. Se señalan también ocurrencias de 'infijos' pues todas las formas pueden ubicarse entre el radical y el modo (real o virtual). Retomamos algunos ejemplos ilustrativos del análisis de Estrada en su descripción morfosintáctica de las 'marcas de actancia' (Estrada 1995:112-124):

Prefijo de primera persona:

c-ĩbad-a "me río, me reí"

c-ik ${ }^{\mathrm{w}}$-a "como, comí"

15 La glosa yuxtalineal es nuestra a partir de los elementos que da el autor en el texto. 
c-i-a "me quemé”

c-a-a "duermo, dormí"

Con infijo:

hĩsi nama-di da-d-ã-di "yo maté venado"

Yo venado-dativo matar-P1S-real-P3SM

Con sufijo:

hũã hĩsi-di pe-e ø-ic-ã-ha "Juan me da (me dió) cazabe a mí"

Juan Yo-dativo cazabe-Clase nominal P3MS-dar-real-P1S

di-a-ha "tengo frío"

frío-real-P1S

Esta autora termina su análisis de valencia verbal con una tabla en la que establece que los sufijos marcan el dativo. El objeto o paciente se indica a través de la marca de clase nominal como en el ejemplo supra "Juan me da cazabe a mí”. Retomamos algunos elementos de la tabla (pg. 123):

Tabla 5: Formas personales en el verbo, sáliba

\begin{tabular}{|l|l|l|}
\hline & Agente (prefijo o infijo) & Dativo (sufijo) \\
\hline P1 & $\mathrm{c} / \mathrm{d}$ & -ha \\
\hline P2 & $\mathrm{k} / \mathrm{k}^{\mathrm{w}}$ & -gi \\
\hline P3M & $ø / \mathrm{h}$ & -di \\
\hline P3F & $\mathrm{x}$ & -xa \\
\hline P1PL & $\mathrm{t}$ & -hadi \\
\hline P3Pl & $\mathrm{h}$ & -di \\
\hline
\end{tabular}

La segunda persona plural es simplemente la pluralización de la forma singular mediante la adición de - do, tanto en los prefijos e infijos como en el sufijo. Igual que en el piaroa, no hay una marca específica.

En el tikuna los predicados sintéticos prefijan el argumento único de intransitivo y agente de transitivos. Los predicados analíticos - que expresarían voz media - usan formas genitivas, análogas a las usadas en la posesión de nombres independientes. Las formas implicadas, retomadas de Montes (2004:122) son:

16 La mayoría de los verbos usa las dos formas de estos paradigmas en función de cambios en la transitividad, algunos verbos se han fijado en una de las dos formas.

17 Jolkesky no considera estos datos. En cambio, incluye erradamente como 'sufijos' CVV las formas del verbo cópula (palabra independiente que va al final de predicados ecuativos y de atribución esencial) que varían en persona en su cuadro de la pág. 25.

18 Variantes dialectales: kui- en tierra firme y ki- en zona ribereña. 
Tabla 6: Formas personales en el verbo, tikuna

\begin{tabular}{|c|c|c|}
\hline & Prefijos $^{16}$ & $\begin{array}{l}\text { Formas libres antepuestas: } \\
\text { PERSONA+GENITIVO }^{17}\end{array}$ \\
\hline P1 & cà-/ cì- & ca-ruu \\
\hline P2 & kù-/ kùì- ${ }^{18}$ & ku-ruu \\
\hline P3M & dã-/ dĩ- & dã-ruu \\
\hline P3F & 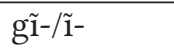 & gĩ-rul, î-ruu \\
\hline P1PL & tà-/ tì- & tà-ruu \\
\hline P2PL & pe-/ pi- & pe-ruu \\
\hline P3Pl & tá-/ tí- & tá-ruu \\
\hline
\end{tabular}

Un ejemplo disponible del yurí (Martius 1863) permite suponer que esta lengua también tenía formas personales formadas con el genitivo:

taröhene "danzar, bailar" (cf. con tikuna tà-ru)

Algunos ejemplos en tikuna con primera persona:

airú cà-daù "veo perro"

perro P1S-ver

cà-dã-kuè "le disparo"

P1S-P3S-disparar

ci-daù "estoy despierto"

P1S-ver

ca-ruu ué "desciendo"

P1S-genitivo descender

Tikuna parece una lengua claramente acusativa; las marcas de persona prefijales o antepuestas, cortas o largas - son 'transparentes' morfológicamente y estables. Sáliba y piaroa tienen paradigmas y distribución diferencial de las marcas de persona en función del tiempo, la modalidad, el carácter activo o no, entre otros factores que aún falta explorar mejor.

Landaburu (2000:278) señala "la semejanza formal de las marcas de actancia verbal con las de dependencia nominal. Se da una gradación entre los radicales léxicos según el comportamiento frente a los índices referenciales: i) radicales sin índice inherente: nominales absolutos; radicales con un índice inherente: nominales relativos y verbales intransitivos; iii) radicales con dos índices inherentes: verbales transitivos".

Esta semejanza formal entre los dos conjuntos, actancia verbal y dependencia nominal, es también característica importante del tikuna. Lo que destacaba Landaburu (2000b:9) para el andoke puede describir la tendencia dominante en tikuna: 
Se distinguen dos clases de predicados: los nominales y los verbales. Tanto el predicado nominal como el verbal integran en su palabra índices argumentales (personales o clasificatorios): con los nominales para indicar posesión, con los verbales para indicar participación. Indices nominales o índices verbales son idénticos.

Los verbales pueden tener hasta dos índices argumentales. Los verbales monovalentes tienen un único paradigma argumental prefijado que representa el argumento involucrado en el proceso intransitivo (puede ser activo o pasivo), o el soporte de cualidad (no hay adjetivos).

Los pocos datos del yurí disponibles parecen mostrar igualmente una cercanía entre las formas de posesión y la actancia, al menos para la primera persona:

tschu-báacki "codo" cf: tsch-ägóhco "bebo"

La identidad y unidad de las formas personales frente a nombres y verbos del andoke y del tikuna aparece también descrita para otras lenguas. En los datos de piapoco, Arawak, de Reinoso (2002:152) se señala una coincidencia parcial entre las formas posesivas que se prefijan al nombre y las formas de agente que se prefijan a los verbos intransitivos. Los transitivos tienen un paradigma parcialmente diferente y los pacientes se derivan morfológicamente de las formas de agente: núa 'yo', $\boldsymbol{n u}$-prefijo con valor posesivo y sujeto verbal: nu-minali 'mi dueño', nu-táita 'yo puedo'. Sin embargo en los estativos hay sufijación del morfema - ni, tercera persona masculina singular, lo que puede compararse con la sufijación en sáliba y piaroa, también relacionada con el caracter estativo.

\section{Pronombres libres}

El sáliba tiene formas libres no siempre coincidentes con las formas prefijales, además exige posponer la marca de clase en algunas de las formas. En contraste, el tikuna tiene 'transparencia' morfológica en las formas personales, pues los pronombres libres son formas largas formadas a partir de los prefijos del nombre y del verbo en tikuna. En esta lengua (datos retomados de Montes 2004:88) se adiciona un sufijo único ${ }^{19}$. El yurín ${ }^{20}$ parece haber tenido

19 No estamos de acuerdo por ello en proponer como forma del 'proto Macro Daha' una forma de $1^{\circ}$ persona como * tVbã (Jolkesky 2009:17-18) que toma como elemento compartido algo que en tikuna no pertenece a la forma personal y que tampoco es exclusivo de estas formas. Igualmente en piaroa esta autor consideró como parte de la forma a comparar una marca de foco que es opcional.

20 Tener en cuenta que la escritura de Martius es de tipo ortográfico mientras que los ejemplos de las otras lenguas están en forma fonológica. Posible interpretación: forma de primera persona más sufijo de genitivo 'mío', igual al tikuna actual 
el mismo conjunto de formas libres y ligadas, quizá con alargamiento vocálico para las formas libres:

Tabla 8: Formas personales libres en tikuna y yurí

\begin{tabular}{|l|l|l|}
\hline $\begin{array}{c}\text { Pronombres } \\
\text { personales } \\
\text { libres }\end{array}$ & \multicolumn{1}{|c|}{$\begin{array}{c}\text { Tikuna } \\
\text { Persona+base pronominal }\end{array}$} & \multicolumn{1}{c|}{ Yurí (Martius, 1863) } \\
\hline P1S & cò-bã, cà-bã & tschuari \\
\hline P2S & kù-bã & wikú, wiú \\
\hline P3SF & gî-bã & \\
\hline P3SM & dũ-bã & niy \\
\hline P1PL & tò-bã & $\begin{array}{l}\text { too } \\
\text { tarö }\end{array}$ \\
\hline & jìe-bấ & \\
\hline P2PL & pé- bã & \\
\hline P3PL & tur-bã & \\
\hline
\end{tabular}

En sáliba Estrada (1995:44) considera como gramemas libres los pronombres personales hĩsi 'yo', ũku 'tú, ãxu 'nosotros'. Las formas de tercera persona sufijan marcas de clase nominal: $h i-x u$ 'ella', jo-ho 'él', hĩ-tu 'ellos, ellas' (ibidem:98). La animacidad, el género y el número en Sáliba-Piaroa son categorías ligadas a la expresión de la tercera persona. En piaroa (datos aportados por Estrada, 2012 21 la situación es análoga, pero hay algunas diferencias interesantes: El pronombre libre $t^{h} i$, 'yo', es monosílabo; uku 'tú' y $x u^{22}$ 'ella' son formas no analizables, mientras que los otros dos pronombres de 3a. persona - ya-hu 'él' y $h i-t^{h} i$ 'ellos, ellas' - incluyen marca de clase nominal. El pronombre $u h u-t u$ 'nosotros' incluye una marca de animado+plural. Ambas lenguas traducen 'ustedes' (P2PL) adicionando a la forma singular - do (¿clase 3 a, animado+colectivo?) en sáliba y -tu en piaroa.

En andoke los índices referenciales (personales y no personales) se combinan directamente con 6 marcas de clase, 3 valores de ubicación temporal y 4 valores de evidencial. Estos pueden además recibir otras marcas, como las de caso. La marca de nominativo para los índices personales es $\{-\mathrm{P} \gamma\}$. Se obtiene así:

$$
\begin{aligned}
& \text { ову 'уо', } \\
& \text { ha?y 'tú', } \\
& \text { kẽ? ̃ 'nosotros', } \\
& \text { kỹ?y 'ustedes'. }
\end{aligned}
$$

21 A partir de una investigación de campo realizada entre 2008 y 2009 sobre esa lengua. 22 Lo que en sáliba es un sufijo de clase nominal en piaroa es un pronombre libre. 
Los pronominales con valor anafórico designan según su clase nominal la entidad. Se construyen sufijando a los índices la forma invariable -ka. Se exceptúa el índice de referenciación indefinida, que no puede construir un pronombre (Landaburu 2000:283).

Respecto a las categorías asociadas a las formas personales, a partir de un análisis de fuentes y datos de diversas lenguas y de otros autores, es pertinente recordar el análisis comparativo de Landaburu (1993:5 traducción nuestra del original en francés):

Estas dos proposiciones [categorización dominante animado/ inanimado y la idea amplia de número] se verifican en un gran número de lenguas de la región comprendida entre la cordillera de los Andes y el río Amazonas, en particular, por las lenguas de la familia lo tucano oriental (...), las lenguas de la familia arawak (...), las lenguas de la familia guahibo (...). En estas lenguas se tiene normalmente un sistema más simple que en andoke. Para el índice actancial de tercera persona con el verbo (...) hallamos una oposición tripartita cuyos dos primeros términos son normalmente masculino y femenino mientras que el tercer término remite de manera por otro lado variable a lo cuantitativo (plurales, colectivos, no contables, etc...). Esta triple oposición se retoma normalmente en el nivel de los determinantes nominales. Del lado del nombre en sí, el animado se distingue a veces del inanimado por que éste último está seguido de clasificado de formas físicas o de figuras.

\section{Otros temas morfosintácticos}

De manera marginal nos referimos a algunos asuntos que tienen interés tipológico y areal, centrales en las lenguas consideradas, y que podrían ser objeto de comparaciones y análisis posteriores.

\section{Clases nominales y género}

Tanto en andoke como en sáliba género y clase nominal son elementos solidarios integrados en la predicación. En sáliba hay concordancia de marcas de clase en el predicado pues las marcas de clase nominal del verbo sáliba son las que representan el objeto en tercera persona en el esquema de 'predicación bifurcada' (Estrada, 1996:168).

Ejemplo:

hũã gu-pe "Juan camina/caminó"

juan caminar-clase nominal 1a (Estrada 1995:109) 
En andoke, de acuerdo las clases nominales se integran plenamente y de manera obligatoria en la estructura predicativa, como se vió en los ejemplos supra:

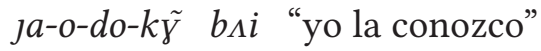

Las oraciones descriptivas de esta lengua (...) tienen un estructura sintáctica dual muy marcada. En ellas una palabra-sujeto se opone al resto del enunciado. La cabeza de esta palabra-sujeto la constituye un índice gramatical que señala la entidad escogida como sujeto de la predicación. 12 índices son posibles en esta posición de sujeto (4 índices personales, 8 índices de género o clases de entidad) (Landaburu 2005:2)

En tikuna, persona y clase nominal son dos paradigmas separados (Montes 2004:61-72). El paradigma de los marcadores de género tiene tres morfemas proclíticos: $\{1\}$ femenino, $\{\mathrm{ya}\}$ masculino, \{ga\} pasado-caduco, que emergen según la posición y función de los sintagmas nominales con respecto al verbo, lo que puede considerarse como una forma de concordancia lábil con respecto a la que la que ha sido descrita para sáliba y menos central en la predicación que la del andoque y su sistema de índices predicativos clasificados para la tercera persona. Si bien el contenido de los sistemas de género-clase nominal y clasificadores puede presentar algunos paralelismos interesantes, estos son rasgos areales en Amazonia y no hay elementos suficientes para postularlos como indicios de parentesco genético. Por otra parte, las especificidades fonológicas y morfológicas de estos elementos dentro de cada lengua no pueden ignorarse.

\section{Deixis, caducidad o modalidad}

Nos parece que en términos comparativos sería pertinente retomar la categoría de 'caducidad' (Jokesky lo llama 'distal 4') y los morfemas que la expresan, pues en sáliba y en tikuna hay formas similares con significado similar pero con diferente distribución (proclítica en tikuna) que habría que comparar sistemáticamente en la región:

$$
\text { ga taudẽkú "verano pasado" }
$$

Clase3:pasado verano

Este contenido semántico de caducidad ligada a lo nominal se encuentra en lenguas Arawak, expresado también a través de sufijos nominales. Así, en achagua, lengua de la Orinoquia, Meléndez (1989:33) identifica el sufijo -mi en el ejemplo /t fawi-mi/ "el tigre de otra época (el que fue tigre)". En piapoco, otra lengua de la Orinoquia, Reinoso (2002:177) encuentra el mismo sufijo del 
achagua y dice que es una "modalidad cognitiva que señala que el hablante tuvo conocimiento de los hechos por medio de evidencias o huellas":

/nu-ba-la-mi-ka/ "la que fue mi pesca" (con la evidencia del pescado ante sí) Ips-pescar-caducidad-real

\section{Hacia un programa de trabajo}

Si en este punto aceptamos la idea de una coincidencia potencialmente interesante entre Sáliba-Piaroa y Tikuna-Yurí (al menos entre subconjuntos de formas personales ligadas a los nombres y a verbos) habría que explicar qué condujo al tikuna a tener formas únicamente prefijales, o qué condujo a Sáliba-Piaroa a adquirir formas sufijales. La omnipresencia de la concordancia de clase en sáliba, una fuente posible de marcadores de persona, es una pista a seguir, dado que una oración posible (desprovista de modo, pero con aspecto) está compuesta por el radical verbal y la marca de clase (Estrada 1995:109):

hũã gu-pe "Juan camina/caminó"

juan caminar-clase nominal 1a

Esta misma autora (pg. 113) propuso que algunas de las marcas se derivan de los pronombres libres y de los demostrativos; retomamos algunos ejemplos de ese análisis:

P1S hĩsi $->\mathrm{s}->\mathrm{c} \rightarrow \mathrm{d}$

P2S $\quad \tilde{\mathrm{k}} \mathrm{u}->\mathrm{ku}->\mathrm{kw}->\mathrm{k}->\mathrm{g}$

P3SM joho $->$ h $->\varnothing$

P3SF hixu $\rightarrow \mathrm{x}$

En el caso del tikuna ¿En qué medida podría atribuirse a contacto y préstamo la presencia de dos formas personales divergentes del Sáliba-Piaroa? La forma de tercera persona singular masculino - que además tiene un valor genérico y no marcado - está presente en lenguas de otras familias que pudieron haber influenciado una amplia área. Por otra parte, la forma de 2 da persona plural también podría ser un préstamo de familias con influjo histórico en el área.

Tanto el sáliba (y el piaroa) como el tikuna y el yurí tuvieron contactos con lenguas de la gran familia Arawak:

En los siglos V-VI se difundió un "modelo" conocido como el "complejo arawak' que puso (o impuso) su sello sobre varios grupos étnicos, según un movimiento norte-sur, desde las riberas del Orinoco hasta más al sur de la ribera derecha del Amazonas. Los grupos así "influenciados" habían adoptado varios rasgos de este 
complejo (organización ritual, rituales, etc.) que, de cierta manera fueron compartidos en el noroeste amazónico (...) Después, a partir del siglo XI, oleadas de poblaciones pertenecientes al conjunto tupí surcaron el río Amazonas e impusieron su modelo sociocultural a las poblaciones encontradas (...) Su modo de organización se impuso sin dificultad, ocupando los sitios antes "arawakizados" (Goulard op. cit.: $\mathrm{x})$

Los resultados de este eventual contacto en la gramática es un asunto que requiere un detallado análisis diacrónico. La influencia Caribe también se expandió en Amazonia y en Orinoquia. Por otra parte, el influjo Tupí es una presencia cierta en la parte de la Amazonia donde se encuentran los Tikunas.

En cuanto a la relación genética postulada a partir de la parcial coincidencia formal entre marcas personales, la discusión parece abierta, pues si bien algunos autores sostienen que estas formas son estables y resistentes al contacto, otros lo cuestionan y encuentran al menos indicios importantes de préstamos de elementos específicos atribuibles al contacto, tanto entre lenguas cercanas genéticamente como entre lenguas de familias diferentes (Siewierska 2004:274). También es aceptado que en situaciones álgidas de contacto y cambio es usual la reestructuración e hibridación muy radical, como lo atestiguan lenguas criollas. Tanto la pérdida completa de los paradigmas de persona como de oposiciones semánticas propias de los mismos, pueden darse en esos casos. Dado que los determinantes últimos de esas situaciones son externos, debido a factores sociopolíticos, la dirección de los procesos de pérdida no será una imagen especular de los procesos de adquisición (Ibidem:281).

- Por ahora descartamos la propuesta de un tronco Macro-Daha que incluya a las lenguas y familias Sáliba-Piaroa, Tikuna-Yurí y Andoke. Se ha considerado que las formas de persona pueden ser elementos relativamente estables en la diacronía y buenos candidatos para indicar parentesco, sin embargo en contextos muy álgidos de contacto y cambio lingüístico esto podría no ser cierto.

- En formas personales hay sin duda unas similaridades fonológicas y distribucionales entre tikuna-yurí y un subconjunto del sálibapiaroa, y estas similaridades no se han encontrado hasta el momento en la misma proporción con otras lenguas y familias. Sin embargo se han señalado las divergencias entre ambas familias que deben también considerarse y explicarse: paradigma sufijal de sáliba y piaroa determinado por la valencia, el carácter activo y el tiempo y la modalidad (entre otros factores que están aún por estudiar).

- Se avala el interés de un programa de trabajo sobre las formas personales, las clases nominales y el género en el contexto del Noroeste Amazónico que contemple los estudios ya publicados sobre 
las familias Tukano, Bora-Miraña, Yagua-Peva, Makú-Puinave y Uitoto.

- En cuanto a la existencia de una categoría de caducidad, asociada al nombre y al verbo, se propone comparar con lo que ocurre en las familias Arawak y Guahibo. Algunos elementos y rasgos de lenguas Arawak deben ser sistemáticamente contrastados ya que la expansión histórica de ese gran conjunto puede ser un elemento clave en el entendimiento de rasgos compartidos.

- Los sistemas de género, clases y clasificadores deben aún considerarse comparativamente, sabiendo que la existencia de sistemas que superponen género y clasificación está extendida también en una amplia área del noroeste amazónico y del borde amazónico.

\section{Referencias}

Brinton, Daniel Garrison. [1891] 1946. La raza americana, (Trad.), Buenos Aires, Editorial Nova.

Cabral, Ana Suelly Arruda Câmara. 1995. Contact-induced language change in the western Amazon: The non-genetic origin of the Kokama language. Tesis doctoral de la Universidad de Pittsburgh dirigida por Susan Berk-Seligson.

Chamberlain, Alexander F. 1913. 'Linguistic Stocks of South American Indians, with Distribution Map'. American Anthropologist, 15:236-247.

Duarte, Fabio Bonfim. 2005. 'Codificação de argumentos e ergatividade (cindida) em Tenetehára’. LIAMES Línguas Indígenas Americanas 5:113-146. Brasil: Universidade de Campinas.

Estrada, Hortensia. 1996. La lengua sáliba. Clases nominales y sistema de concordancia, Premios Nacionales de Colcultura 1995, Tercer Mundo Editores, Santafé de Bogotá.

Gilij, Felipe Salvador. [1780] 1965. Ensayo de historia americana, (Trad.) ts. I-III, Academia Nacional de Historia, Caracas.

Gómez-Imbert, Elsa y Ospina, Ana María. 2010. Informe científico del Proyecto C08H01 Tipología fonológica y gramatical de las lenguas amazónicas y andinas de Colombia. Impreso. Bogotá: COLCIENCIAS-ICETEX-Ecos Nord.

Goulard, Jean Pierre y Montes, María E. Yurí/Juri. En prensa.

Goulard, Jean Pierre (Comp.). 2011. 'El nor-oeste amazónico en 1776. Expediente sobre cumplimiento de la Real Cédula dada en San Ildefonso, a 2 de septiembre de 1772' En: Serie Documentos históricos del Imani, 1. Leticia, Amazonas, Colombia: Universidad Nacional-Instituto Amazónico de investigaciones Imani.

Jolkesky, Marcelo. 2009. 'Macro-Daha: reconstrução de um tronco lingüístico do noroeste amazônico', En: ROSAE - I Congreso Internacional de Lingüística Histórica 26-29 de julo de 2009. Salvador, Bahía. Disponible en línea en: http:// sites.google.com/site/marcelojolkesky/ Acceso en octubre de 2011. 
Landaburu, Jon y Roberto Pineda. 1984. Tradiciones de la gente del Hacha, Mitología de los indios andoques del Amazonas. Bogota: UNESCO- Instituto Caro y Cuervo.

Landaburu, Jon. 1993. 'Quand le nombre est un genre en andoke et en quelques autres langues amérindiennes de Colombie’. Faits de langues 1(2):145-159. Francia. URL http://www.persee.fr/web/revues. Consultado el 13 octubre, 2011.

Landaburu, Jon. 2000. 'La lengua andoke’. En: González de Pérez, María Stella y Rodríguez de Montes, María Luisa (coordinación científica y editorial) Lenguas indígenas de Colombia: Una visión descriptiva. Bogotá: Instituto Caro y Cuervo, Multiletras Editores Ltda, pp. 285-288.

Landaburu, Jon. 2000b. 'Entre sintaxis y pragmática. El surgimiento de una estructura predicativa' (Reelaboración de: Landaburu, Jon. 2000. 'Estructuración de la oración: ejemplos amazónicos y andinos' En: Congreso de lenguas indígenas de Suramérica. Lima: Universidad Ricardo Palma). URL http://lanic.utexas.edu/project/etext/ llilas/cilla/landaburu.pdf. Consultado el 13 de octubre, 2011.

Landaburu, Jon. 2005. 'Expresión gramatical de lo epistémico en algunas lenguas del norte de Suramérica" URL: http://lanic.utexas.edu/project/etext/llilas/cilla/ landaburu2.pdf Consultado el 13 octobre, 2011.

Loukotka, Čestmír. 1935. Clasificación de las lenguas sudamericanas. Edición Lingüística Sudamericana, núm. 1. Praga.

Martius, Karl Friedrich Philip von. 1867. Beiträge zur Ethnographie und Sprachenkunde Amerikas zumal Brasiliens I. Zur Ethnographie. Leipzig: Friedrich Fleischer. URL http://biblio.etnolinguistica.org Consultado el 13 octobre 2011.

Martius, K. F. P. von, 1863. Glossarium linguarum brasiliensium, Munchen.

Meléndez, Miguel. 1989 'El nominal en Achagua’, en: Lenguas aborígenes de Colombia, serie Descripciones \#4, Orinoquia. Bogotá: Universidad de Los Andes.

Monsonyi, Esteban Emilio. 2000. 'Breve caracterización conjunta del curripaco y del piapoco’. En: González de Pérez, María Stella y Rodríguez de Montes, María Luisa (coordinación científica y editorial) Lenguas indígenas de Colombia: una visión descriptiva. Bogotá: Instituto Caro y Cuervo, Multiletras Editores, pp. 641-656.

Monsonyi, Esteban Emilio. 2000. 'Elementos gramaticales del idioma piaroa'. En: González de Pérez, María Stella y Rodríguez de Montes, María Luisa (coordinación científica y editorial) Lenguas indígenas de Colombia: una visión descriptiva. Bogotá: Instituto Caro y Cuervo, Multiletras Editores, pp. 657-668.

Montes Rodríguez, M. E. 2004. Morfosintaxis de la lengua tikuna (Amazonia colombiana). Bogotá: Colección Lenguas Aborígenes de Colombia, Serie Descripciones, \# 15. Universidad de Los Andes-CESO-CCELA.

Montes Rodríguez, María Emilia. 2004. 'Género, clasificadores y nombres inalienables en tikuna, una mirada areal', ponencia presentada al X Congreso de Antropología en Colombia. Manizales, Universidad de Caldas.

Orphão de Carvalho, Fernando. 2009. 'On the genetic kinship of the languages Tikúna and Yurí'. Revista Brasileira de Lingüística Antropológica 1(2):247-268. Brasilia: Universidad de Brasilia. 
Queixalós F. y O. Renault-Lescure (eds.). 2000. As línguas amazônicas hoje, IRD/ISA/ MPEG, São Paulo. URL: http://www.cartographie.ird.fr/sphaera/pays.php.

Reinoso, Andrés. 2002. Elementos para una gramática piapoco. Bogotá: Ministerio de Cultura, Premios Nacionales de Cultura.

Rivet, Paul. 1920. 'Affinités de Sáliba et du Piaroa'. Fournal de la Societé des Américanistes. Nouvelle Série, t. XII. Paris.

Siewierska, Anna. 2004. Person. Cambridge: Cambridge Textbooks in Linguistics.

Data recebimento: 01/10/2012

Data aceite: 27/05/2013 